\title{
The Demand for (Micro) Health Insurance in the Informal Sector
}

\author{
David M. Dror ${ }^{\mathrm{a}, \mathrm{b}}$ and Lucy A. Firth \\ ${ }^{a}$ Micro Insurance Academy, 52-B, Okhla Industrial Estate phase III, New Delhi 110020, India. \\ E-mails: daviddror@socialre.org; Lucy.firth1@gmail.com \\ ${ }^{b}$ Erasmus University Rotterdam (Institute of Health Policy and Management), PO Box 1738, \\ Rotterdam 3000DR, The Netherlands.
}

We identify the need for a theory of demand for health insurance suited to the informal sector in low- and middle income countries (LMIC) where some 3 billion people lack health cover. Excluded from formal governance structures, they rely on informal arrangements by which rulesin-use shape choices, behaviours and decisions. We explore the fundamental assumptions of standard economic theories of demand for health insurance in the light of arguments from the literature and field evidence. We show that the assumptions are largely inconsistent with the context of poverty and informality. And we propose a new theory based on assumptions better suited to the context of informality and poverty. Our major conclusion is that, in order to grow the demand for health insurance in the informal sector in LMIC, it is first necessary to strengthen ground-up governance consistent with group-based decision-making under local conditions. The Geneva Papers (2014) 39, 693-711. doi:10.1057/gpp.2014.24

Keywords: theory of demand; low- and middle income countries; informal sector; micro insurance; health insurance; governance; community-based health insurance

Article submitted 17 June 2013; accepted 27 May 2014; published online 16 July 2014

The online version of this article is available Open Access

\section{Introduction}

Most of the world's population in low- and middle income countries (LMIC) lives and works in the informal sector. ${ }^{1}$ In the developing world, the informal sector means small-scale, selfemployed activities (with or without hired workers), typically unrecorded, unregistered and conducted without proper integration with the administrative machinery responsible for enforcing laws and regulations, usually escaping both the attention of and recognition from the authorities. ${ }^{2}$

The strong incentive to be in this informal context is that people are outside the framework through which most countries collect taxes or dedicated contributions. The down sides are numerous, notably being de facto excluded from the practical engagements of governments to recognise a universal "right to health" for all citizens ${ }^{3}$ through constitutions or engagements under international conventions and recommendations ${ }^{4}$ notably, the WHO

\footnotetext{
${ }^{1}$ Pratap and Quintin (2006); Bacchetta et al. (2009).

${ }^{2}$ ILO (2000).

${ }^{3}$ Dror (2001).

${ }^{4}$ Backman et al. (2008).
} 
decision on universal health coverage (UHC). ${ }^{5}$ Health insurance is a favoured road towards achieving UHC in most LMIC. ${ }^{6}$ While health insurance has the potential to reduce out-ofpocket payments (that the poor in the informal sector of developing nations make for health care) and improve access to necessary health care (that is often foregone when unaffordable), ${ }^{7}$ health insurance penetration rates in the informal sector are very low. ${ }^{8}$ This low penetration raises an underlying question: If the benefits of health insurance are positively provable, how can theory explain the conditions under which the 3 billion or so in the informal sector of LMIC would seek voluntary health insurance?

While governments of LMIC have a central role in delivering health services to population segments in the informal sector, their ability to fund such services through taxation is severely limited when the untaxed informal sector is larger than the taxed formal sector, ${ }^{9}$ and their ability to expand service delivery through insurance is compromised by lack of capacity to enforce mandated affiliation, ${ }^{10}$ which is aggravated further when the mandate entails premium payments. ${ }^{11}$ This combined constraint suggests that affiliation to health insurance in the informal sector would probably have to be voluntary and contributory. ${ }^{12}$ Thus, the question how can theory explain the conditions under which the 3 billion or so in the informal sector of LMIC would seek voluntary and contributory health insurance? begs a convincing answer that, we submit, the theories on health insurance do not yet provide.

The plan of this paper is that: in the next section, we draw on the literature and on evidence from the field to analyse the applicability of the core assumptions of conventional economic theories of demand for health insurance to the context of poverty and informality. In the subsequent section, we propose a theory structured by eight conditions that together provide a contextualised explanation of the demand for health insurance in the informal sector of LMIC. The last section contains our conclusions and policy recommendations on how to establish conditions under which the population in the informal sector of LMIC would seek voluntary and contributory health insurance.

\section{Review of conventional theories of the demand for health insurance}

In this section, we review the main assumptions that form the tenets of conventional economic theories of the demand for insurance generally and health insurance particularly. Starting from common historic origins, based on marginal values, and posited on "perfect knowledge", conventional theories differ from one another on various issues. Here, we focus on differing treatments of attitude to risk (i.e. Friedman and Savage vs Kahneman and Tversky) and of moral hazard (i.e. Pauly vs Nyman) to show that the conventional economic theoretic approach is, in general, ill-suited to the context of poverty in informal sectors. We have organised our

\footnotetext{
${ }^{5}$ WHO (2005).

${ }^{6}$ Faden et al. (2011).

${ }^{7}$ Mielck et al. (2009).

${ }^{8}$ Roth et al. (2007); De Bock and Gelade (2012).

${ }^{9}$ Narayan et al. (2000a, b); Backman et al. (2008).

${ }^{10}$ Navarro (1989); Narayan et al. (2000a, b).

${ }^{11}$ Gumber (2002).

${ }^{12}$ Dror (2007).
} 
investigation of the relevance of conventional theories in this section under three groups of assumptions, those relating to expected utility, attitudes to risk and moral hazard.

\section{Assumptions relating to expected utility}

The conventional treatment of the demand for health insurance has its genesis in the theories of diminishing marginal utility and expected utility, both of which were developed in relation to gambles, and are attributed to Bernoulli $1738 .^{13}$ The law of diminishing marginal utility states that the first unit of consumption of a good or service (or income or wealth) yields more utility than the second and subsequent units, with a continuing reduction of utility for greater amounts. The expected utility hypothesis states that the utility from the expected value of a gamble will depend on the gamblers' risk appetite and exposure. The method to measure utility in terms of income or wealth for the rational decision-maker under conditions of uncertainty was developed by von Neumann and Morgenstern ${ }^{14}$ as a function of probability and attitude to risk. Marginal and expected utility theory has been extensively discussed in the literature (e.g. the 2007 commemorative edition of von Neumann and Morgenstern has been cited 16,000 times by May 2013) and analysed in microeconomic courses, ${ }^{15}$ but the relevance of its embedded assumptions and their application to the demand for health insurance in the informal sector have not been systematically explored. Here we do so for a selection of assumptions.

Conventional assumption: the decision to buy (health) insurance is taken by individuals in return for an expected payoff to them

Three issues are at the core here: individual decision-making, individual payoff and specific monetised sums. The independence of individual choice must be nuanced in the context of the informal sector. ${ }^{16}$ Based on historically seated de facto attributes of governance structures (with norms, protocols and local rules-in-use), communities create consensus and influence decisions adopted by single community members. ${ }^{17}$ The group priorities uphold decisions that are commonly considered to be welfare-enhancing. ${ }^{18}$ In traditional and informal sectors, this creates a powerful pressure on individual members that determines what economic activity they can/must/must not enter into, who can/cannot do so, and how the benefits will be distributed. ${ }^{19}$ Applying to health insurance the insight that communities prioritise welfare-enhancing choices, it follows that the consensus would uphold the decision to buy health insurance only when the contracted benefits of the insurance can be expected to flow to community members. This is consistent with the seminal micro health insurance work of Dror and Jacquier ${ }^{20}$ that proposed that the basis for decision-making in micro health insurance was group consensus, and supported by recent evidence from rural India. ${ }^{21}$

\footnotetext{
13 Arrow (1963).

${ }^{14}$ von Neumann and Morgenstern (1947).

${ }^{15}$ For example, Varian (1990).

${ }^{16}$ Platteau (1997).

${ }^{17}$ Granovetter (1973); Ostrom (2010).

${ }^{18}$ Sen $(1970,1999 a, b)$.

${ }^{19}$ Crawford and Ostrom (2005).

${ }^{20}$ Dror and Jacquier (1999).

${ }^{21}$ Dror et al. (2014a).
} 
Compliance by community members with consensus flows from their reliance on the community's patterns of reciprocity. ${ }^{22}$ Moreover, non-conformity with the consensus could be understood by other group members as a form of not meeting expectations of reciprocity, which can lead to punishment in the form of partial or total exclusion from the group. ${ }^{23}$ The need to belong to the group, implying access to benefits that are generated by the members but not otherwise available widely as public goods, reinforces the norms and networks that enable individuals to act collectively, also known as "social capital". ${ }^{24}$ Informal communities may have stronger and more pervasive impacts on their members than do formal communities ${ }^{25}$ because the threat of exclusion for noncompliance may not be as significant with formal groups. This is consistent with the findings of Zhang et al. ${ }^{26}$ and Donfouet et al. ${ }^{27}$ for China and Cameroon, respectively. We posit that these arguments and findings challenge the fundamentally different assumption about the direct association between paying a premium in expectation of a specific payoff from an insurance contract.

Conventional assumption: people have no cover other than formally contracted insurance Although not formally stated, conventional theory rests on the simplifying assumption that either people have bought insurance or they do not have insurance, suggesting that there is no cover for those who are not "formally" insured. Von Neumann and Morgenstern's axiom of independence of preferences, which relies on the separation of risks, may not be widely applicable in the context in which there is informal cover of many risks from birth through the community's systems of reciprocity that are typical within the informal sector, ${ }^{28}$ and which are akin to informal mutual insurance. ${ }^{29}$ Works by Graham, ${ }^{30}$ Stiglitz $^{31}$ and Linnerooth-Bayer and Mechler $^{32}$ have investigated preexisting informal cover in developing contexts and found that although such arrangements were intended for times of need, in practice they were sometimes vague, unpredictable, incomplete and unstable due to constraints associated with covariance of risk across the group. While the separation of risks is apparently violated in the informal context, others have investigated the complementarity between private and public insurance, but have done so in the formal context of developed countries. ${ }^{33}$ Morduch, ${ }^{34}$ in a review of informal health and other insurances, provides evidence suggesting that the limitations of arrangements that prevail in the informal sector generate a desire to

22 Granovetter $(1973,2005)$.

${ }^{23}$ Henrich et al. (2001).

${ }^{24}$ Woolcock and Narayan (2000).

${ }^{25}$ Granovetter (1985).

${ }^{26}$ Zhang et al. (2006).

27 Donfouet et al. (2011).

${ }^{28}$ Narayan et al. (2000a).

${ }^{29}$ Coate and Ravallion (1993).

30 Graham (1994).

31 Stiglitz (2004).

${ }^{32}$ Linnerooth-Bayer and Mechler (2007).

${ }^{33}$ For example, Nyman (2003); Preker and Bassett (2013).

${ }^{34}$ Morduch (1999). 
systematise and strengthen the imperfect dependence between risk and pre-existing informal mutual-aid through formal health insurance.

Conventional assumption: individuals have access to adequate information and knowledge to understand the value proposition of health insurance

Fundamental to making an informed choice to buy health insurance based on the expected utility is the ability to understand the value-proposition of the payoff. There are at least three issues here. The first is that levels of technical knowledge and awareness of health insurance may be very low in the informal sector ${ }^{35}$ making it difficult for individuals to perceive the value proposition. The paradigm of transacting under information asymmetry or imperfect knowledge is known. ${ }^{36}$ Secondly, qualities of health insurance as a credence good ${ }^{37}$ might exacerbate difficulties in understanding its value proposition. Moreover, the value proposition of health insurance may be less clear when related to group-based interests, and to the need that health insurance should be complementary to pre-existing informal cover and/or to services that can be accessed free-of-charge. The third issue is that, contrary to excellent intra-community information-flows (e.g. gossip), flows of information between external parties and informal sector interlocutors are typically highly constrained, ${ }^{38}$ subject to deliberate misleading ${ }^{39}$ and extensively misinterpreted. ${ }^{35}$ Occasional mis-selling, deliberate over-simplification or obfuscation on the part of the insurer and the insured has made (health) insurance the butt of endless jokes and court cases; they also challenge the assumption that adequate information and knowledge to understand the value proposition of health insurance is a given. This assumption is challenged not just by intentional lack of transparency that is often part of the business model of commercial companies in developing countries (von Pischke), but also by the fact that the poor in the informal sector have no inkling of what they need to know or how to access the information they seek because of their lack of experience in making such contracts. ${ }^{40}$ In the words of Donald Rumsfeld in a totally different context they face "unknown unknowns". ${ }^{41}$

Moreover, in the informal sector, many people's only experience of insurance is the mandatory credit life insurance required when borrowing money, which is a further financial burden at a time of need and, as such, builds antagonism towards insurance. ${ }^{42}$ Whether negative perceptions of insurance are gained directly or vicariously, local information sources ${ }^{38}$ ensure that all within the community know the perils of insurance, which impacts the community's consensus on the benefits of health insurance and knowledge of its value proposition.

\footnotetext{
35 Platteau and Ontiveros (2013).

${ }^{36}$ Akerlof (1970); Simon (1972); Stiglitz (2001).

${ }^{37}$ Credence goods are goods and services for which the value can only be ascertained when characteristics are tested sometime after the transaction is complete (Baron, 2011).

38 Granovetter (1973).

39 von Pischke (2008); Narayan et al. (2000a, b).

40 von Pischke (2008); Gandhi (1959).

${ }^{41}$ Donald Rumsfeld, American Secretary of State 2002 (on the issue of Iraq's supposed weapons of mass destruction), "There are known knowns; there are things we know we know. We also know there are known unknowns; that is to say, we know there are some things we do not know. But there are also unknown unknowns - the ones we don't know we don't know".

${ }^{42}$ Roth et al. (2007).
} 
698

Conventional assumption: willingness to pay is a monetised expression of marginal utility, which is expressed as demand

Another basic premise of neoclassical economics is that demand, as manifest in willingness to pay (WTP), is equivalent to marginal utility, ${ }^{15}$ which suggests the utility maximising framing of "what do I want/need and how much am I prepared to pay for it?" ${ }^{40}$ Does this also apply in the informal sector? A review of 14 evidence-based studies of WTP for health insurance among the poor in low-income countries in Asia and in Africa demonstrated that evaluation of WTP was influenced by socioeconomic parameters (e.g. income, education, morbidity patterns, availability of health care). Furthermore, marked differences in these parameters across locations and over time made it very difficult to associate estimated WTP with the actuarial pure premium or the price of benefits on offer. In fact, when WTP was measured as a per cent of their income, the poorer sub-groups within resource-poor population segments expressed higher WTP than the richer subgroups for identical packages. ${ }^{43}$ A more general model of WTP in rural settings (based on data from India) found that, in all locations, WTP expressed as percentage of income decreases with household income. This reminds of Engel's law on food expenditures; and WTP as percentage of food expenditures had the most consistent relationship with WTP (other anchors examined included WTP as per cent of overall income and discretionary income). ${ }^{44}$ That WTP is influenced by other things than income is perhaps not surprising, but that it is negatively associated with income is counterintuitive and important to stress. These findings indicate that like food, health insurance is considered a necessity good even by people with very low income and no prior experience with health insurance. This may echo von Pischke's explanation of a different logic among poor people in the informal sector (demonstrated in the context of borrowing money) whereby the poor do not consider whether the price (interest rate) is reasonable and whether they can gain on the deal overall, but whether they can meet the repayment schedule and whether it will enable them to meet a need or an obligation. This suggests that the decision to purchase insurance in the informal context might be framed as "how much can I afford not to participate in this transaction?" Therefore, in the informal sector there is no certainty that the assumption holds that WTP for health insurance is the monetised value of the marginal utility of the expected benefits.

Conventional assumption: that exchange occurs in an environment of predictable certainty Two important, often unstated premises are that consumers are able to enter into insurance contracts at will, and can assume that the insurer will fulfil the contract or that such fulfilment can be enforced. Neither of these premises may hold in the informal sector: the individual's capacity to enter into contracts may be curtailed in contexts where group-based institutions can "prescribe, permit or advise" individual actions (p. 583) ${ }^{19}$; and there is constrained access to external rules of law. ${ }^{45}$ Although expected value theory has been applied elsewhere to cover the possibility of contract failure, ${ }^{46}$ this probability-based extension of theory may not be relevant in the informal sector where

${ }^{43}$ Dror and Koren (2011).

${ }^{44}$ Binnendijk et al. (2013).

45 Narayan et al. (2000a, b); Straub (2005).

${ }^{46}$ Doherty and Schlesinger (1991). 
there are fundamental difficulties in establishing and enforcing contracts. The capacity of low-income countries to provide governance of transactions is limited ${ }^{47,48}$ both within the informal sector and between informal and formal segments of the economy. Exclusion from the governance arrangements of the formal sector exposes people in the informal sector to greater transaction costs related to contract enforceability. ${ }^{49}$ The efforts, costs and risks of transaction failure "have particularly damaging effects, as they undermine the very processes of exchange and specialization". 50 Therefore, we assert that in the informal sector, the environment of predictable certainty cannot be assumed to exist, or is severely hampered.

\section{Assumptions relating to attitudes to risk}

Friedman and Savage ${ }^{51}$ specified insurance as a gamble in which the risk-averse individual will prefer a certain gain to an uncertain gain of equivalent expected value. Applying the law of diminishing marginal utility, because utility increases with wealth at a decreasing rate, riskaverse people prefer a certain gain to an uncertain gain of the equivalent value, therefore insurance is rational. It also shows that poorer people benefit more from insurance of a given monetary sum. Kahneman and Tversky ${ }^{52}$ argued that insurance relates to potential loss (rather than a gain) and showed that as the rational individual will prefer an uncertain loss over a certain loss of equivalent expected value, purchasing insurance in order to avoid risk is not rational.

We now examine whether the assumptions associated with these arguments hold.

Conventional assumption: the demand for (health) insurance is demand for certain outcomes over uncertain ones of equal value

Evidence from LMIC indicates that people seeking insurance seek certainty of payment rather than certainty of expected value. The informal sector is characterised by a general deficit of formal governance and predictability, which relates not merely to extremely rare events. In fact, Platteau ${ }^{16}$ explained that the norms of balanced reciprocity require that all should be able to receive payoffs in a reasonable period, which could be met better when insurance covers higher frequency events with fairly certain occurrences. The quest for that kind of certainty among rural poor was reported in studies that recorded the choices when asked to compose the health insurance package; rural poor people in the informal sector in India devised composite packages with low per-event maximum cover above which the insurance does not pay anything ("caps") plus outpatient care and maternity, rather than a

\footnotetext{
${ }^{47}$ Knack (2003).

${ }^{48}$ Governance consists of the traditions and institutions by which authority is exercised. This includes the capacity of the government to effectively formulate and implement sound policies; and the respect of citizens and the state for the institutions that govern economic and social interactions among them. The Rule of Law "captures perceptions of the extent to which agents have confidence in and abide by the rules of society, and in particular the quality of contract enforcement, property rights, the police, and the courts, as well as the likelihood of crime and violence" www.info.worldbank.org/governance/wgi/index.asp, (World Bank (yearly) and World Bank (year unknown))

49 Williamson (1981, 1989, 1985 and 2003).

${ }^{50}$ Kydd and Dorward (2003, pp. 5-6).

${ }^{51}$ Friedman and Savage (1948).

52 Kahneman and Tversky (1979).
} 
package of only hospitalisation with higher coverage. ${ }^{53}$ Moreover, where communities organise their community-based health insurance (CBHI) schemes in which members participate in package design, the poor in the informal sector in India seek to avoid uncertainty in health-care costs by including high frequency events the costs of which they perceive as less predictable (e.g. tests or imaging) and leave out services for which the price is both lower and predictable (e.g. consultation). ${ }^{54}$ These packages offered many members a higher likelihood to draw some benefit. Such packages are not usually offered by commercial insurers in India.

An additional element of uncertainty is the cost of financing the payment to health-care providers, called "hardship financing". ${ }^{55,56}$ Hardship financing can represent as much as 5 per cent of households' annual income in the informal sector of rural India, and is associated not only with hospitalisations but also with cases of maternity and even outpatient care (some 25 per cent of the households reported hardship financing in outpatient cases). Therefore, the "demand for fairly certain outcomes" should include the fairly certain reduction of the risk of hardship financing, which occurs in most types of health-seeking, and thus it follows logically that its reduction would take precedence over reducing only rarer risks, for example, hospitalisations. However, health insurance never compensates for the interest paid to moneylenders for loans to pay for uninsured health costs ("hardship financing"). Commercially available insurance packages that neither reduce health-related borrowing by covering frequent events, nor cover hardship financing are unlikely to be viewed by most people in the informal sector as a mechanism enhancing certain outcomes. Therefore, we posit that conventional assumptions of attitude to risk are irrelevant not only because of their reliance on marginal utility but also because they are ill suited to application to the risks faced in the informal context.

\section{Assumptions relating to moral hazard}

The trade-off between risk sharing and incentives to change behaviour was identified by Arrow ${ }^{13}$ who argued that doctors' mediation of access to medical services could control any tendency to moral hazard. ${ }^{57}$ Pauly $^{58}$ assumed a stronger role for the patient/consumer in moral hazard. He reasoned that the value of health insurance to the consumer (price pay-off insurance contracts only, not lump sum contracts ${ }^{59}$ ) originates from his/her ability to consume health care at a price below the efficient marginal cost price which results in demand for a quantity of health care above the efficient level. Pauly argued that moral hazard is inefficient because the price the insured consumer pays is below the efficient market price, which she/he would pay if uninsured. When that cost difference is greater than the gain from

${ }^{53}$ Danis et al. (2007); Dror et al. (2007b).

${ }^{54}$ Dror (2007a); Panda et al. (2013, Table 1); Dror et al. (2014b, Tables 2 and 3).

55 Hardship financing refers to selling assets or borrowing at interest to pay for health care, which is the single greatest cause of families falling into poverty in low and middle income countries.

56 Binnendijk et al. (2012).

57 "Moral hazard" refers to changes in behaviour due to being insured.

58 Pauly (1968).

${ }^{59}$ Price payoff insurance contracts pay an agreed amount of a health-care cost (e.g. $\$ 50$ towards the cost of a physician consultation) thus reducing the price paid for health care by the insured party. Contingent contracts pay an agreed amount upon diagnosis (e.g. \$500 if diagnosed with appendicitis). 
the avoidance of risk (Friedman and Savage), there is a net overall welfare loss to all insured. ${ }^{60}$ Zeckhauser $^{61}$ and others have shown that co-payments, exclusions and discrimination on the basis of medical condition reduce demand-driven moral hazard and lessen inefficiencies. This led to the introduction of deductibles and co-payments into insurance policies, on the assumption that it was an effective way to remedy the welfare loss due to moral hazard. Shifting some of the cost to the policyholders meant a net increase in the cost of health insurance (or lower payout for the risk premium). Pauly et al. ${ }^{62}$ argued that riskaverse customers would agree to pay even higher premiums (than actuarially fair) as long as they are cheaper than their expected expenses for the same basket of services without insurance, and therefore consistent with rational behaviour. However, Pauly recognised that demand for health insurance would weaken when the variance of the medical costs covered by the insurance is low.

Wagstaff and Lindelow ${ }^{63}$ reported that in China, being insured increased the risk of high and catastrophic spending rather than lowering it, because of insurer-induced moral hazard and encouragement to seek care from higher-level providers. Such a situation could mean that uninsured are required to pay lower prices than insured persons, which would lower the potential gain from insurance. This invalidates the assumption that the demand for health insurance would always increase due to expected moral hazard. In most discussions with grassroots groups (and in many professional meetings as well) the common perception is that providers of care charge the insured higher prices than from uninsured. ${ }^{64}$ In the informal sector in countries like India, such pricing practices would lead to higher rather than lower costs when insured, because the standard practice of health insurance is not to charge a deductible or co-pay, but to impose low caps (maximum cover above which the insurer does not pay anything). Therefore, the only opportunity to benefit from moral hazard would be for low-cost procedures, the prices of which are known, competition higher and price variance low. These conditions indicate that, in the informal sector, the assumption that the demand for health insurance is enhanced by moral hazard does not hold.

Nyman $^{65}$ recognised that the sick have health-care costs that reduce their disposable income, a situation that is inexistent among healthy insured. This is an application to health insurance of Arrow's assertion that "medical services, apart from preventive services, afford satisfaction only in the event of illness, a departure from the normal state of affairs" (p. 948). ${ }^{13}$ In other words, moral hazard happens when price elasticity for demand is significantly different from zero, which is the case for non-catastrophic illness treatments, but not necessarily for catastrophic treatments (e.g. amputations or cancer treatments). Nyman argues that lower prices paid by the insured for health care lead not only to a price effect, but also to an income effect that is comparable with a redistribution of income from the insured well to the insured sick. ${ }^{66}$ By enabling the sick to buy needed health care that they could otherwise not afford, insurance leads to a welfare gain for the insured sick

\footnotetext{
60 Pauly (1986).

${ }^{61}$ Zeckhauser (1970).

${ }^{62}$ Pauly et al. (2009).

${ }^{63}$ Wagstaff and Lindelow (2008).

${ }^{64}$ Aikins and Okang (2006).

65 Nyman (2003, 2008).

${ }^{66}$ Nyman (2006).
} 
(efficient moral hazard). Nyman's work complements and extends Pauly's work by identifying that while the price elasticity of demand may or may not be significantly different from zero for any individual, price and income elasticities of the sick will vary greatly from those of the well. Nyman explains the demand for health insurance thus: "consumers demand health insurance mostly to obtain a welfare gain from moral hazard. Consumer preferences regarding risk are largely irrelevant and, if anything, inhibit the purchase of health insurance. Under the new theory, the voluntary purchase of insurance makes consumers better off' (p. xiv). ${ }^{65}$ Typically, in the informal sector, the population under-utilises necessary health care $^{67}$; thus an increase in utilisation following insurance is welfare-enhancing rather than welfare-decreasing moral hazard, and this is true not only for the seriously sick.

Conventional assumption: individuals purchase health insurance in order to take advantage of prices below marginal cost; and they can access the information to do so

Pauly's assumption that consumers have the information and capacities to assess the cost they would face for a particular health treatment when insured vs uninsured has been questioned. ${ }^{68}$ And Knowles ${ }^{69}$ stated that the assumptions of marginal cost pricing and of access to the necessary information by consumers are at odds with the reality prevailing in the health sector (not only in the informal sector). In addition, not only is there a general lack of competitive supply of health care in the informal sector, providers of health services (e.g. government, nonprofit health organisations or informal providers) do not compete with each other on prices or even know their marginal costs. ${ }^{70}$ The prospect of price-effect moral hazard is further reduced in community-based health insurance schemes that can detect, stop or punish members that abuse the $\mathrm{CBHI} .{ }^{71}$ Moreover, as many health insurance schemes offer very limited coverage, the likelihood is greatly diminished to take advantage through insurance of prices below marginal costs, simply because expensive health care (including for life-threatening conditions) depends on the patients' ability to pay out-of-pocket (regardless of insurance status). This suggests that as most costs are excluded from coverage (either not insured at all, or above the cap of insurance) the demand for health insurance in the informal sector cannot be attributed to the desire to capture price reductions that may or may not be below marginal costs through insurance. It would seem that demand reflects a desire to access care affordably.

\section{Conventional assumption: there is ample supply of health care to meet demand}

Though rarely stated by conventional arguments, they rely on an implied assumption that ample and competitive supply of health care exists to satisfy the extra demand generated by the price effect of insurance. As already stated, there is no reason to assume that the fragmented supply of health care in the informal sector is either ample to satisfy the demand or competitive, as Kupferman and Ron ${ }^{72}$ showed in the Philippines, or that it is price sensitive. ${ }^{73}$ Therefore, the assumption must be treated with reserve.

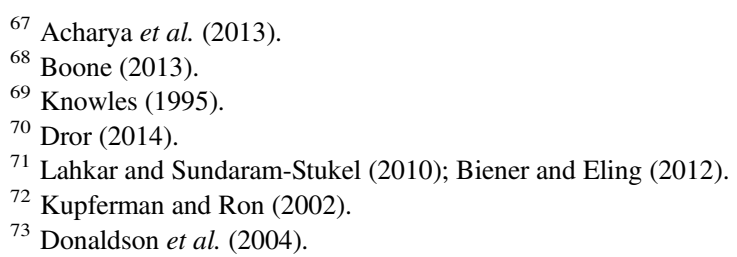


Conventional assumption: the demand for health insurance is the demand to obtain "income effect" benefits, that is, transfer from healthy insured to sick insured

Nyman $^{65}$ explains the income effect (i.e. flows of funds from healthy insured to sick insured) in the context of catastrophic expenses of serious illness (e.g. cancer), but as already mentioned, high-cost events are not normally insurable under health insurance that can be accessed in the informal sector. It could be claimed that the income effect kicks in even with smaller quantum transfers associated with low to medium health-care costs that are relevant to insurance in the informal sector. However, the empirical evidence of the income effect is yet to be shown; in the informal sector, this assertion would apply only when the enrollees have certainty that the contract (which means redistribution from healthy insured to unhealthy insured) is applied fairly and fully, a condition that is neither explicit in policies nor guaranteed. Moreover, as most of the health insurance in the informal sector has been reported to be in the form of mutual-aid or CBHI schemes in India and Africa, the additional question which needs addressing is whether this income effect applies in the same manner when benefits from insurance are sought at the community rather than individual level.

\section{Towards a theory of demand for health insurance in the informal sector}

The discussion in the previous section raised several issues pointing to theoretical inadequacies to explain the conditions under which the 3 billion or so in the informal sector of LMIC would seek voluntary health insurance, when at present most people in the informal sector of developing countries do not join health insurance, even though they pay for health care. Our analysis of the conventional theoretic assumptions leads us to posit that a new theory of the demand for health insurance in the informal sector, based on relevant, workable assumptions is required. As a starting point, a relevant theory must recognise and accommodate the following conditions:

1. The demand is a collective decision of a specific group to formalise and expand preexisting informal arrangements for financial support of its members when ill;

2. A necessary (but not sufficient) condition for the formulation of demand for health insurance in the informal sector is that practical arrangements in place ensure clients that their contract will be enforced;

3. The demand reflects an intention to reduce financial risks from frequent low to medium health-care costs rather than rare health-care costs;

4. The formulation of demand can occur when a consensus is apparent on the value of health insurance within the context, even though the relevant value may differ from the monetised marginal value to each individual;

5. The demand can be expected to increase when moral hazard is welfare enhancing (i.e. when more sick people that did not utilise health care without insurance are getting more needed care when insured);

6. The demand reflects the intention to reduce the risk of hardship financing associated with fairly certain events;

7. The demand can occur either under profit-sharing mutual aid or under profit-taking commercial insurance, either of which can formulate even without competition;

8. The demand for health insurance can be combined with other community activities (i.e. may not be limited to health insurance). 
In this context, a theory of demand must cover not only purchase decisions (which include both decisions of rationing and of priority-setting) but also governance arrangements and relationships with supply. Therefore, we offer this explanation of the demand for health insurance in informal contexts of poverty in LMIC as a more relevant and useful theory. Health insurance is a mechanism through which communities seek to enhance the welfare of members. Demand can be manifested only when the community, applying its rules-in-use, recognises that purchasing health insurance is welfare enhancing and consistent with "what responsible adults should do" to increase the likelihood of benefits to most of the members. Owing to information problems, demand decisions occur through affiliation with groups, rather than through isolated transactions of individuals with partners they do not know and with whom they have little experience transacting. Appropriate, local governance constitutes the necessary but not sufficient driver for the establishment of the health insurance market. Supply, wherever sourced, can capture local demand only when it is trusted, and trust is enhanced when the local rules of governance apply. As demand is the only condition that can drive the creation of a health insurance market, and can only do so with locally trusted governance, the establishment of markets for health insurance must begin with establishing demand at the community level.

This presentation of an alternative explanation of demand in the informal sector is at variance with conventional theories, which have been analysed in the previous section and are summarised below.

One can group the theories of demand for health insurance into two families: those that deal with risk aversion and loss aversion; and those that elaborate moral hazard.

Conventional EU theory of demand is based firstly on the axiom that events are independent from each other. The informal sector with its rural or urban-slum settings offers many challenges to that assumption, and supports a more plausible assumption that the covariant component of health risks predominates. Think of well-documented conditions such as lack of access to safe drinking water; dearth of hygiene or open defecation near or into water sources; malnutrition or under-nutrition; higher likelihood of contracting illnesses from other humans due to communal living of many people in small and enclosed spaces that frequently enforce contact with ill persons even as they do not offer protection from too much heat or cold or air pollution due to indoor cooking; or higher likelihood of contracting illnesses from animals - both domestic and wild-due to close and frequent contact with animals. This leads us to submit that in the informal sector, the violation of the axiom of independence of health events seems undeniable, weakening any argument based on it.

Secondly, the expected marginal utility theory assumes that risk-averse individuals accept a reduction in their wealth if such reduction (i.e. the payment of a premium) could guarantee to escape the risky situation. The four italicised terms are all seriously compromised in the informal sector. The detailed analysis in the previous section shows why most economic decisions are not taken by single individuals or motivated only by personal interests; rather, decisions are taken by a larger human collectivity (the family, the extended family and even the reference group or the "community") of which each person is part. Even if formally a decision could be traced to a single individual, that person's group of significant others influences the decision how much money to spend, when, and for what. The trade-offs of an individual considering only his/her needs often differ fundamentally from those of the group of which she/he is part (e.g. buy something only for my personal use vs pay for health care for a sick relative, or to feed the family, or for a child's school, or for seeds for the next agricultural season, or save up to pay for a wedding or a festival). The group decision reflects not only ROI but 
social priorities and rules-in-use. Moreover, the call to pay a premium to reduce an intangible risk that has not yet occurred (against a promise by an external party that may not be trusted to keep its part of the bargain, or that may legitimately not be required to pay) competes directly with the call to pay for apparent needs against unconditional delivery of good or service. All previous theories have remained silent on the question whether voluntary purchase of a credence good differed from purchasing a normal good even among resource-poor groups; we submit that (at least) in the informal sector, such assumption is invalid, as in fact there is a circumstantial (and theoretical) hierarchy of priorities, which the group shares and its members most often follow. The other assumption, that one person's wealth commands priority over the wealth or well-being of the entire household or community, is also devoid of evidence in the informal sector; in fact, we have provided many references that the collective good often has priority over individual choices because the common good is inclusive and distributive while the individual utility is exclusive and proprietary.

Moreover, the assumption that payment of a premium can guarantee the reduction of risk to wealth subsumes that contracts can be enforced with acceptable costs, risk or time-loss, which is anything but proven in the informal sector. Based on the field evidence cited, we submit that in the informal sector of LMIC, social contracts within community members are backstopped by community pressure to abide by rules-in-use, mostly reciprocity that requires entire families to step in to meet obligations undertaken by their members. Legal contracts with external parties are handled by external arbitrators with a different logic, cost and time frame, and therefore often not accessed at all by informal sector persons.

Finally, we examine the assumption about the risky situation: in addition to the covariate characteristics of risks themselves (explained above), attitudes to risk (risk appetite or aversion) exhibit a covariate component originating from the influence of the majority of the reference community on attitudes held by single individuals. When most people prefer uncertain losses (as postulated by the Prospect theory) that leads them to logically refrain from premium payments that represent a certain loss, most individuals in that community are less likely to opt for a certain loss just to demonstrate their completely independent choice.

Many of the auxiliary assumptions about the conditions under which health insurance operates subsume perfect market conditions (e.g. that insurance is the only or most economical option to pool risks; or that individuals can make informed choices; or that individuals can estimate the monetised value of their marginal utility from health insurance and are willing to pay that amount for any level of risk exposure in isolation of all alternative utility gains that can be availed by other uses of the same amount; or that the transaction occurs in a market obeying predictable rules). All have been shown to be compromised in the informal sector. The cumulative effect of these imperfections weighs heavily on the validity of those theories of demand for health insurance, at least in the conditions prevailing in the informal sector of LMIC.

A different order of theoretical arguments is that voluntary demand for insurance occurs among risk-averse customers to reduce both the risk of high out-of-pocket payments and the variance of such payments. The underlying logic here is that demand for health insurance is the demand of premium payers to tacitly transfer the excessive $\operatorname{cost}^{74}$ to

\footnotetext{
${ }^{74}$ Excessive costs in this context means the difference between the cost that an uninsured would have to pay minus the cost that the insured has to pay, including the premium and any co-pay or deductible amount.
} 
others ("others" means society at large according to Pauly, and the group of healthy insured according to Nyman). That demand can exist when health-care costs are high and variable. This form of demand for insurance is the demand to engage in a win-lose paradigm (the gain of each insured that is paid a claim is the loss of other non-claimants). This expression of the transaction ignores several fundamental situations that are important in the informal sector: (i) members of CBHI often select high-frequency and low cost events for their insurance but leave out high cost benefits because the premium would be too high. As this demand for coverage of lower costs (and probably low variance of OOPS) is not explained by this theory, we must assume it is incomplete; (ii) the theory ignores the possibility that poorer people would avoid OOPS by foregoing care. This is not a rare phenomenon, which is more prevalent in low-income groups (which are of course more prevalent in the informal sector of LMIC). However, people foregoing unaffordable care may still seek assistance from others in their reference community; could this form of pooling and reciprocity explain the demand to be part of a welfareenhancing group? (iii) In LMIC generally, and in the informal sector and CBHI specifically, even insured persons must pay the cost of health care above the cap, which can be considerable. In such cases, the demand for health insurance cannot be the expectation to avoid catastrophic costs (and the definition of "catastrophic" is secondary). A more likely explanation is that the demand reflects an expectation to participate in the network through which people can borrow easily to cover above-cap costs (which, as shown earlier, occasion hardship financing). Maintaining a good standing with potential lenders is very valuable in this case, even if it does not allow transferring either healthcare costs or the cost of hardship financing to others. (iv) Finally, it has been proposed that the demand for health insurance is explained by an expectation that insurance would reduce the variance of high out-of-pocket payments. This expectation subsumes that providers fix prices freely and that there is ample supply to allow price competition. And, that the effective way to reduce variance in the costs is to increase the size of the pool (in application of the Law of Large Numbers). Two observations challenge this line of argumentation in the informal sector: first, in the informal sector the most effective social context is the community, which can be effective for as long as it remains relatively homogeneous and small. Several communities can federate if they wish to capture the benefits of larger size, but the basic unit must remain small. Secondly, there is ample evidence that supply of health care and supply of health insurance is extremely limited in the informal and rural sectors of LMIC, obviating the assumption that price competition can be countered by a large pool of insured clients.

\section{Conclusion and policy implications}

This article set out to answer the question how can theory explain the conditions under which the 3 billion or so in the informal sector of LMIC would seek voluntary health insurance?

The first insight from this analysis is that people in the informal sector seek welfare enhancements through affiliation with groups, rather than through isolated transactions with partners they do not know and with whom they have little experience transacting. Therefore, the demand for health insurance is contingent on groups agreeing that most of their members can gain welfare from engaging in this transaction. 
The second important insight is that perfect market conditions, ${ }^{75}$ which are assumed by conventional theories of health insurance in rich countries, are not met in the informal sector of LMIC. Rather, governance constitutes the necessary but not sufficient driver for the establishment of the health insurance market. Supply, wherever sourced, can capture local demand only when it is trusted, and trust is enhanced when the local rules of governance apply. Demand is the necessary and sufficient condition for the creation of a health insurance market. However, the demand can be manifested only when the community, applying its rules-in-use, recognises that purchasing health insurance is welfare enhancing and consistent with "what responsible adults should do". The community could create such consensus only when the health insurance scheme is governed by rules people understand and accept, which local governance can ensure well. Only when community-based governance is manifest, will its member households express WTP for health insurance and so create solvent demand on which viable supply can be based.

Thirdly, WTP reflects group consensus on the value of the good/service to all members of the community, which means that very rare events are less likely to be perceived as welfare enhancing by most. Therefore, health insurance covering only rare events, even when provided at discounted cost (as some countries do with "below poverty line" populations segments), does not per se guarantee that most people will see it as adding welfare to the community, since the measure is different from price only. Health insurance is perceived as a necessity good, not a normal good, and WTP determined heuristically notably by consensus on the amount that all or most can pay, rather than the actuarial value of out-of-pocket payments that the insurance is supposed to replace. Therefore, increases in WTP for health insurance over time would depend on increases in the community's perception of the welfare gains, rather than on higher input prices of providers, or additional services in the benefit package that most people neither need nor are likely to claim.

The policy implication of our analysis why most assumptions of conventional theories of demand are violated, and our alternative theory of demand in the informal sector is that governments and all those wishing to see more demand for voluntary and contributory health insurance in the informal sector of LMIC can assist the process by supporting the propagation of (i) bottom-up governance structures among communities in the informal sector; and (ii) the perception that health insurance enhances welfare to the entire community, rather than to single individuals. Only when communities are comfortable about the governance of their health insurance are the conditions ripe for expression of WTP, which in turn determines the supply of health insurance. Therefore the 3 billion or so in the informal sector of LMIC would seek voluntary health insurance only when local awareness about the welfare gains of health insurance is widespread, supported by local governance. As these are the drivers for the development of the market for (micro) health insurance in the informal sector, they should be facilitated and enhanced by institutions of state and by the business community.

75 Including free and full information on transactions, ample comparable supply which enables free competition based on price and quality of services; ample demand that is keen to buy; and governance structures ensuring that contracts can be enforced and that are known and trusted by most clients. There is not one LMIC that can boast ample supply either of health services or of health insurance in its informal sector, or that has efficient governance that ensures contract enforcement in matters of credence goods like insurance and that the majority of the population trusts. 


\section{Acknowledgements}

The authors acknowledge the support of the Micro Insurance Academy in providing the opportunity for this work. We also acknowledge the useful comments by Ruth Koren on an earlier draft, as well as those by two peer reviewers. David M. Dror gratefully acknowledges funding support provided by the European Commission 7th Framework Program (grant ID HEALTH-F2-2009-223518 - Communitybased Health Insurance in India).

\section{References}

Acharya, A., Vellakkal, S., Taylor, F., Masset, E., Satija, A., Burke, M. and Ebrahim, S. (2013) The impact of health insurance schemes for the informal sector in low- and middle-income countries: a systematic review, World Bank Research Paper 6324.

Aikins, M. and Okang, G. (2006) Utilization and Cost of Health Care Under the District Health Insurance Schemes: A Case Study of Brong-Ahafo and Eastern Regions, Accra: JSA Consultants.

Akerlof, G.A. (1970) 'The market for "lemons": Quality uncertainty and the market mechanism', Quarterly Journal of Economics 84(3): 488-500.

Arrow, Ken. J. (1963) 'Uncertainty and the welfare economics of medical care', American Economic Review 53(5): 941-973.

Bacchetta, M., Ekkehard, E. and Bustamante, J. (2009) Globalization and Informal Jobs in Developing Countries, Geneva: International Labour Organization.

Backman, G., Hunt, P., Khosla, R., Jaramillo-Strouss, C., Mekuria Fikre, B., Rumble, C., Pevalin, D., Acurio Páez, D., Armijos Pineda, M., Frisancho, A., Tarco, D., Motlagh, M., Farcasanu, D. and Vladescu, C. (2008) 'Health systems and the right to health: An assessment of 194 countries', The Lancet 372(9655): 2047-2085.

Baron, D.P. (2011) 'Credence attributes, voluntary organizations, and social pressure', Journal of Public Economics 95(11/12): 1331-1338.

Biener, C. and Eling, M. (2012) 'Insurability in microinsurance markets: An analysis of problems and potential solutions', The Geneva Papers on Risk and Insurance-Issues and Practice 37(1): 77-107.

Binnendijk, E., Dror, D., Gerelle, E. and Koren, R. (2013) 'Estimating willingness-to-pay for health insurance among rural poor in India, by reference to Engel's law', Social Science and Medicine 76(1): 67-73.

Binnendijk, E., Koren, R. and Dror, D.M. (2012) 'Hardship financing of healthcare among rural poor in Orissa, India', BMC Health Services Research 12: 23.

Boone, J. (2013) Does the market choose optimal health insurance coverage? TILEC Discussion Paper No. $2013-$ 008, from www.papers.ssrn.com/sol3/papers.cfm?abstract_id=2240172, accessed June 2014.

Coate, S. and Ravallion, M. (1993) 'Reciprocity without commitment: Characterization and performance of informal insurance arrangements', Journal of Development Economics 40(1): 1-24.

Crawford, S. and Ostrom, E. (2005) 'A grammar of institutions', in E. Ostrom (ed.) Understanding Institutional Diversity, Princeton, NJ: Princeton University Press, pp. 137-174.

Danis, M., Binnendijk, E., Vellakkal, S., Ost, A., Koren, R. and Dror, D.M. (2007) 'Eliciting health insurance benefit choices of low income groups', Economic and Political Weekly 42(32): 3331-3339.

De Bock, O. and Gelade, W. (2012) The Demand for Micro-Insurance: A Literature Review, Geneva: International Labour Office (ILO).

Doherty, N.A. and Schlesinger, H. (1991) 'Rational insurance purchasing: Consideration of contract nonperformance', in J.D. Cummins and R.A. Derring (eds.) Managing the Insolvency Risk of Insurance Companies, the Netherlands: Springer, pp. 283-294.

Donaldson, C., Gerard, K., Mitton, C., Jan, S. and Wiseman, V. (2004) Economics of Health Care Financing: The Visible Hand, Basingstoke, UK: Palgrave Macmillan, pp. 298-464.

Donfouet, H.P., Essombè Edimo, J.-R., Mahieu, P.-A. and Malin, E. (2011) 'Social capital and willingness-to-pay for community-based health insurance in rural cameroon', Global Journal of Health Science 3(1): 142-149.

Dror, D. (2007) 'Why “one-size-fits-all” health insurance products are unsuitable for low-income persons in the informal economy in India', Asian Economic Review 49(1): 47-56. 
Dror, D.M. (2001) 'Reinsurance of health insurance for the informal sector', Bulletin of the World Health Organization 79(7): 672-678.

Dror, D.M. (2014) 'Health microinsurance programs in developing countries', in A.J. Culyer (ed.) Encyclopedia of Health Economics. Vol. 1, San Diego: Elsevier, pp. 412-421.

Dror, D.M. and Jacquier, E. (1999) 'Micro-insurance: Extending health insurance to the excluded', International Social Security Review 52(1): 71-97.

Dror, D.M. and Koren, R. (2011) 'The elusive quest for estimates of willingness to pay for health micro insurance among the poor in low-income countries', in C. Churchill and M. Matul (eds.) Micro Insurance Compendium II. 2012, Chapter 7. Geneva: ILO, pp. 156-173.

Dror, D.M., Radermacher, R. and Koren, R. (2007a) 'Willingness to pay for health insurance among rural and poor persons: Field evidence from seven micro health insurance units in India', Health Policy 82(1): 12-27.

Dror, D.M., Koren, R., Ost, A., Binnendijk, E., Vellakkal, S. and Danis, M. (2007b) 'Health insurance benefit packages prioritized by low-income clients in India: Three criteria to estimate effectiveness of choice', Social Science \& Medicine. 2007 64(4): 884-896.

Dror, D.M., Panda, P., May, C., Majumdar, A. and Koren, R. (2014a) “"One for all and all for one”; Consensusbuilding within communities in rural India on their health microinsurance package', Risk Management and Healthcare Policy. June 2014, Vol 2014;1 doi: http://dx.doi.org/10.2147/RMHP.S66011.

Dror, D.M., Majumdar, A., Panda, P.K., John, D. and Koren, R. (2014b) 'Implementing a participatory model of micro health insurance among rural poor, with evidence from Nepal', The Geneva Papers on Risk and Insurance-Issues and Practice 39(April): 280-303.

Faden, L., Vialle-Valentin, C., Ross-Degnan, D. and Wagner, A. (2011) The role of health insurance in the costeffective use of medicines, Working Paper 2, Drug Policy Research Group and WHO Collaborating Center in Pharmaceutical Policy, from www.haiweb.org/medicineprices/24072012/HealthinsurancefinalMay2011.pdf, accessed June 2014.

Friedman, M. and Savage, L.J. (1948) 'The utility analysis of choices involving risk', Journal of Political Economy 56(4): 279-304.

Gandhi, M. (1959) India of My Dreams, Delhi: Rajpal and Sons.

Graham, C. (1994) Safety Nets, Politics, and the Poor: Transitions to Market Economies, Washington: Brookings Inst Press.

Granovetter, M. (1973) 'The strength of weak ties', American Journal of Sociology 78(6): 1360-1380.

Granovetter, M. (1985) 'Economic action and social structure: The problem of embeddedness', American Journal of Sociology 91(3): 481-510.

Granovetter, M. (2005) 'The impact of social structure on economic outcomes', Journal of Economic Perspectives 19(1): 33-50.

Gumber, A. (2002) Health insurance for the informal sector: Problems and prospects, Working Paper No. 90, Indian Council for Research on International Economic Relations, from www.icrier.org/pdf/WP-90.pdf, accessed June 2014.

Henrich, J., Boyd, R., Bowles, S., Camerer, C., Fehr, E., Gintis, H. and McElreath, R. (2001) 'Cooperation, reciprocity and punishment in fifteen small-scale societies', American Economic Review 91(2): 73-78.

ILO (International Labour Organisation) (2000) The informal sector UN, Bangkok 2000, from www.ilo.org/public/ english/region/asro/bangkok/feature/inf_sect.htm, accessed May 2013.

Kahneman, D. and Tversky, A. (1979) 'Prospect theory: An analysis of decisions under risk', Econometrica 47(2): 263-291.

Knack, S.F. (2003) Democracy, Governance, and Growth, Michigan: University of Michigan Press.

Knowles, J.C. (1995) 'Research note: Price uncertainty and the demand for health care', Health Policy Plan 10(3): 301-303.

Kupferman, A. and Ron, A. (2002) Structuring Demand and Supply in Community Health in Philippine Insurance, in Social Reinsurance: A New Approach to Sustainable Community Health Financing, Washington: World Bank and International Labour Organisation.

Kydd, J. and Dorward, A. (2003) Implications of market and coordination failures for rural development in least developed countries, Paper presented at the Development Studies Association Annual Conference, Strathclyde University, Glasgow, 10-12 September.

Lahkar, R. and Sundaram-Stukel, R. (2010) 'Protecting the poor through community based health insurance', in 6th Annual Conference on Economic Growth and Development, Indian Statistical Institute, New Delhi, 17 December. 
710

Linnerooth-Bayer, J. and Mechler, R. (2007) 'Disaster safety nets for developing countries: Extending public-private partnerships', Environmental Hazards 7(1): 54-61.

Mielck, A., Kiess, R., von dem Knesebeck, O., Stirbu, I. and Kunst, A.E. (2009) 'Association between forgone care and household income among the elderly in five Western European countries-analyses based on survey data from the SHARE-study', BMC Health Services Research 9: 52.

Morduch, J. (1999) 'Between the state and the market: Can informal insurance patch the safety net?' The World Bank Research Observer 14(2): 187-207.

Narayan, D., Patel, R., Schafft, K., Rademacher, A. and Koch-Schulte, S. (2000a) Voices of the Poor: Can Anyone Hear Us?, Washington, DC: World Bank and Oxford University Press.

Narayan, D., Chambers, R., Shah, M.K. and Petesch, P. (2000b) Voices of the Poor: Crying out for Change, Washington, DC: World Bank and Oxford University Press.

Navarro, V. (1989) 'Why some countries have national health insurance, others have national health services, and the United States has neither', International Journal of Health Services 19(3): 383-404.

Nyman, J.A. (2003) The Theory of Demand for Health Insurance, Stanford: Stanford University Press.

Nyman, J.A. (2006) 'Evaluating health insurance: A review of the theoretical foundations', The Geneva Papers 31(4): 720-738.

Nyman, J.A. (2008) 'Health insurance theory: The case of the missing welfare gain', European Journal of Health Economics 9(4): 369-380.

Ostrom, E. (2010) 'Beyond markets and states: Polycentric governance of complex economic systems', American Economic Review 100(3): 641-672.

Panda, P., Chakraborty, A., Dror, D.M. and Bedi, A. (2013) 'Enrolment in community-based health insurance schemes in rural Bihar and Uttar Pradesh, India', Health Policy and Planning. doi:10.1093/heapol/ czt077.

Preker, A. and Bassett, M. (2013) From Cradle to Grave in the United Kingdom, Canada, Australia, and Elsewhere, in Scaling Up Affordable Health Insurance, New York: World Bank.

Pauly, M.V. (1968) 'The economics of moral hazard: Comment', American Economic Review 58(3): 531.

Pauly, M.V. (1986) 'Taxation, health insurance, and market failure in the medical economy', Journal of Economic Literature XXIV(2): 629-675.

Pauly, M.V., Blavin, F.E. and Meghan, S. (2009) 'How private, voluntary health insurance can work in developing countries', Health Affairs 28(6): 1778-1787.

Platteau, J.-P. (1997) 'Mutual insurance as an elusive concept in traditional rural communities', The Journal of Development Studies 33(6): 764-796.

Platteau, J.-P. and Ontiveros, D.U. (2013) Understanding and information failures: Lessons from a health microinsurance program in India, ILO Research Paper, (29) Geneva.

Pratap, S. and Quintin, E. (2006) The informal sector in developing countries: Output, assets and employment (No. 2006/130), Research paper, UNU-WIDER, United Nations University (UNU).

Roth, J., McCord, M. and Liber, D. (2007) 'The landscape of microinsurance in the world's 100 poorest countries', MicroInsurance Centre, from www.microinsurancecentre.org/resources/documents/doc_details/634-the-landscape-of-microinsurance-in-the-worlds-100-poorest-countries-in-english.html, accessed June 2014.

Sen, A. (1970) Collective Choice and Social Welfare, San Francisco: Holden-Day.

Sen, A. (1999a) 'The possibility of social choice', The American Economic Review 89(3): 349-378.

Sen, A. (1999b) Reason before Identity (The Romanes Lecture for 1998), Oxford: Oxford University Press.

Simon, H. (1972) 'Theories of bounded rationality', in C. McGuire and R. Radner (eds.) Decision and Organization, Amsterdam: North-Holland Publishing Company, pp. 161-176.

Stiglitz, J. (2001) 'Information and the change in the paradigm in economics', Nobel Lecture at Colombia Business School, from www.nobelprize.org/nobel_prizes/economics/laureates/2001/stiglitz-lecture.pdf, accessed June 2014.

Stiglitz, J.E. (2004) 'Globalization and growth in emerging markets', Journal of Policy Modeling 26(4): 465-484.

Straub, S. (2005) 'Informal sector: The credit market channel', Journal of Development Economics 78(2): $299-321$. Varian, H.R. (1990) Intermediate Microeconomics: A Modern Approach, New York: W.W. Norton.

von Neumann, J. and Morgenstern, O. (1947) Theory of Games and Economic Behavior, Princeton: Princeton University Press.

von Pischke, J.D. (2008) 'Gandhi vs gauss: Ethical issues in micro and small business finance', Savings and Development 32(3): 127-152. 
Wagstaff, A. and Lindelow, M. (2008) 'Can insurance increase financial risk?: The curious case of health insurance in China', Journal of Health Economics 27(4): 990-1005.

WHO (2005) 'WHA58.33 Sustainable Health Financing, Universal Coverage and Social Health Insurance', from www.apps.who.int/iris/bitstream/10665/20383/1/WHA58_33-en.pdf May 2013, accessed June 2014.

Williamson, O.E. (1981) 'The economics of organization: The transaction cost approach', American Journal of Sociology 87(3): 548-577.

Williamson, O.E. (1985) The Economic Institutions of Capitalism, New York: The Free Press.

Williamson, O.E. (1989) 'Transaction cost economics', in R. Schmalensee and R.D. Willig (eds.) Handbook of Industrial Organization. Vol. 1, Handbook in Economics, Amsterdam: North Holland, pp. 135-182.

Williamson, O.E. (2003) 'Examining economic organization through the lens of contract', Industrial and Corporate Change 12(4): 917-942.

Woolcock, M. and Narayan, D. (2000) 'Social capital: Implications for development theory, research, and policy', The World Bank Research Observer 15(2): 225-249.

World Bank (yearly) 'World Wide Governance Indicators', from www.info.worldbank.org/governance/wgi/index .asp.

World Bank (year unknown) 'Definition of Rule of Law' (title unknown), March 2013, from www.info.worldbank .org/governance/wgi/pdf/rl.pdf), accessed June 2014.

Zeckhauser, R. (1970) 'Medical insurance: A case study of the tradeoff between risk spreading and appropriate incentives', Journal of Economic Theory 2(1): 10-26.

Zhang, L., Wang, H., Wang, L. and Hsiao, W. (2006) 'Social capital and farmer's willingness-to-join a newly established community-based health insurance in rural China', Social Science \& Medicine 67(7): 1173-1182.

\section{About the Authors}

David M. Dror has 30+ years of research and management experience. His research focuses on explaining the low insurance uptake in the informal sector in low-income countries, and developing effective implementation processes of insurance rooted in evidence of "what works" at the base-of-the-pyramid. He has published extensively; served as Honorary. Professor at Erasmus University's Institute of Health Policy and Management; worked with ILO Social Security Department; and Founded the Micro Insurance Academy where he acts as Chairman and managing director.

Lucy Firth has extensive experience as a researcher and manager with a focus on innovation for positive social outcomes. Her interest in micro insurance stems from her belief in it as a system-based innovation with the potential to promote prosperous development by protecting vulnerable populations from unexpected costs. Having worked for the UN, Australian governments, Melbourne University and industry, she is now focusing on creative support for the not-for-profit sector and running her own micro agribusiness.

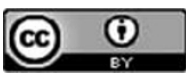

This work is licensed under a Creative Commons Attribution 3.0 Unported License The images or other third party material in this article are included in the article's Creative Commons license, unless indicated otherwise in the credit line; if the material is not included under the Creative Commons license, users will need to obtain permission from the license holder to reproduce the material. To view a copy of this license, visit http://creativecommons.org/licenses/by/3.0/ 